\title{
Malignant tumors in two ancient populations: An approach to historical tumor epidemiology
}

\author{
ANDREAS G. NERLICH ${ }^{1}$, HELMUT ROHRBACH ${ }^{1}$, BEATRICE BACHMEIER ${ }^{2}$ and ALBERT ZINK $^{1}$ \\ ${ }^{1}$ Institute of Pathology, Academic Hospital Munich-Bogenhausen, Englschalkingerstr. 77, D-81925 \\ München; ${ }^{2}$ Department of Clinical Chemistry and Clinical Biochemistry, Surgical Clinic, \\ Ludwig-Maximilians University Munich, Nussbaumstr. 10, D-80336 München, Germany
}

Received December 27, 2005; Accepted February 15, 2006

\begin{abstract}
The actual increase in the rate of malignant tumors has been ascribed to a higher life expectancy and the influence of various environmental factors. Herein, we present data on the frequency of malignant tumors in paleopathologically well-defined historic populations. Thereby, we looked for malignant growth affecting the skeleton in three study populations of 905 individuals that have been excavated from the necropoles of Thebes-West and Abydos, Upper Egypt covering the time period between 3200 and $500 \mathrm{BC}$ and 2547 individuals that have been buried in a Southern German ossuary dating from between AD 1400 and 1800. The tissue preservation of both the Egyptian and Southern German material was excellent. All available specimens were subjected to a very careful macroscopic examination; isolated findings were also radiologically investigated. In parallel, anthropological data, such as gender and age at death, were recorded. We identified 5 cases of malignant tumors affecting the skeleton in the Egyptian material and 13 cases affecting the skeletal material from Southern Germany. In most instances, multiple osteolytic lesions with slight osteoblastic reaction are strongly suggestive for metastatic carcinoma. Few cases with poorly reactive osteolyses were most compatible with plasmacytoma. Relative tumor frequencies on an age- and sex-adjusted population basis (using a mathematic model of skeletal involvement of malignant tumors in a well-defined English study population from AD 1901 to 1905) indicated that the tumor rates were not statistically different between ancient Egyptian, the historical Southern German and the recent English reference population. These observations indicate that malignant tumors were present in spatially and temporarily different populations over the last 4000 years with an ageand gender-adjusted frequency not different from Western
\end{abstract}

Correspondence to: Professor A. Nerlich, Institut für Pathologie, Klinikum München-Bogenhausen, Englschalkingerstr. 77, D-81925 München, Germany

E-mail: andreas.nerlich@extern.lrz-muenchen.de

Key words: paleoepidemiology, ancient Egypt, Middle Ages, tumor frequency, carcinoma metastasis, plasmacytoma industrial populations of c. 100 years ago. Therefore, we conclude that the current rise in tumor frequencies in present populations is much more related to the higher life expectancy than primary environmental or genetic factors.

\section{Introduction}

The currently high rates of malignant tumors in Western industrialized populations have been ascribed to an increase in the life expectancy and increasing influence of environmental factors, in particular nutritional intake of potentially carcinogenic substances and air pollution. It can be assumed that these factors have undergone substantial changes during various periods of time, which seem to have affected historic populations to variable extent. The analysis of tumor frequencies in temporarily different populations may thus uncover the role of those factors on carcinogenesis.

To this regard, there exist only very few previous reports describing the residues of malignant tumors in historic populations of different time and localization (1-3). Accordingly, it has been assumed that the rate of malignant tumors in historic populations was low (4). A systematic compilation of data from the literature, assumed to cover almost all currently available references on this subject, describes out of 342 tumor cases only 126 cases with clear evidence for malignant tumor growth and 25 further cases with potentially malignant diagnosis (Nerlich et al, unpublished data).

Due to the wealth of preserved mummy material, most cases with malignant growth properties have been identified in the human remains from ancient Egypt. Thus, up to now 39 malignant tumors have been described showing either primary or secondary manifestation of the skeleton $(1,2,5)$. These come from various periods and places of the Pharaonic Egypt and provide clear evidence that malignant tumors were present in ancient Egypt. Due to the assumption that malignant growth was a rare event in those times, this has led to the notion that carcinogenic influences would have been small in those ancient populations. In a recent publication, however, we could demonstrate that the estimated malignant tumor rate was comparable to that of a Middle European population of AD 1900-1905 provided that a careful palaeopathological examination uncovered all cases available (5-7).

In the present study, we extend our previous observations and describe further cases from ancient Egypt, as well as the 


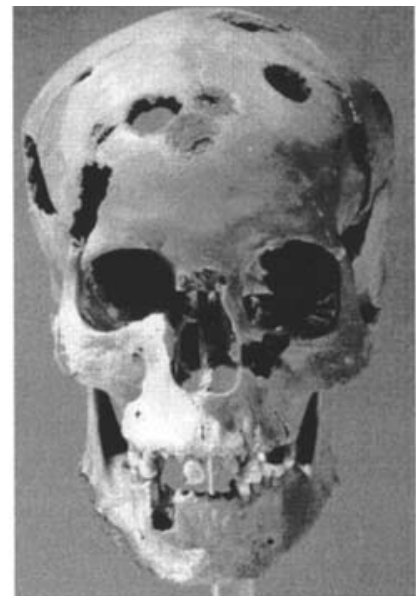

A

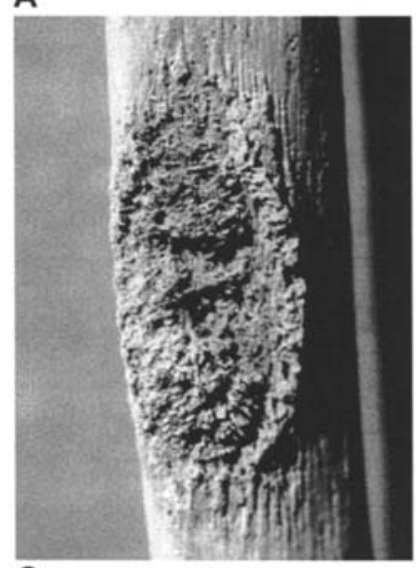

C

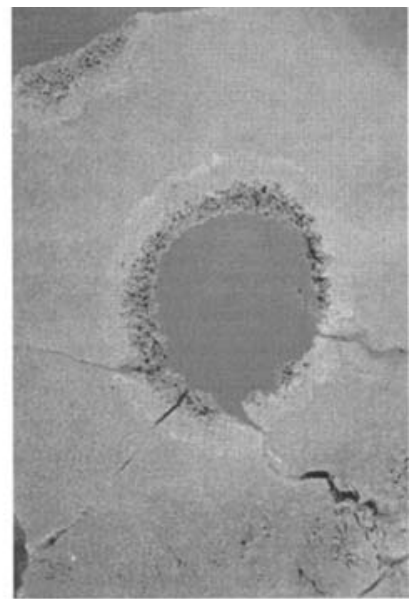

B

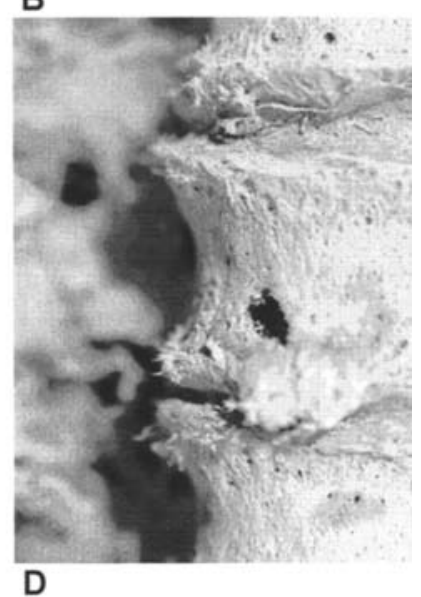

D

Figure 1. Macroscopic aspects of malignant tumors in ancient Egyptian skeletons. (A) Adult female skull with multiple osteolyses (case 1). (B) Close-up view of (A) showing minor osteoblastic reaction at the margin of the lesion. This strongly suggests bone metastasis. (C) Superficial osteoblasticosteolytic bone tumor in case 2 showing partial destruction of the bone and marginal osseous reaction. (D) Osteolysis of vertebral body (case 4) suggestive of plasmacytoma (multiple myeloma). The lesion, such as multiple others in this case, revealed almost no osseous reaction.

paleopathological findings in a second study population that comes from a Southern German ossuary housing, the human remains of a small city dating between AD 1400 and 1800 . Using this extended database, we provide not only novel data on the occurrence of malignant tumors in past populations but show the upcoming value of tumor paleoepidemiology. By use of this approach, the influences of living conditions, extension of life expectancy and role of external potentially carcinogenic substances may be evaluated.

\section{Material and methods}

\section{Description of study populations}

Ancient Egyptian material. The basis for this study comes from extensive paleopathological studies on two major necropolis of ancient Egypt which covers three major time periods.

The skeletal remains from the pre- to early dynastic cemetery of Abydos (c. 3200-2900 BC) cover presently 189 individuals that have been buried close to the royal tombs, which suggest higher social status of those individuals (8). They have been only lightly embalmed so that mostly only

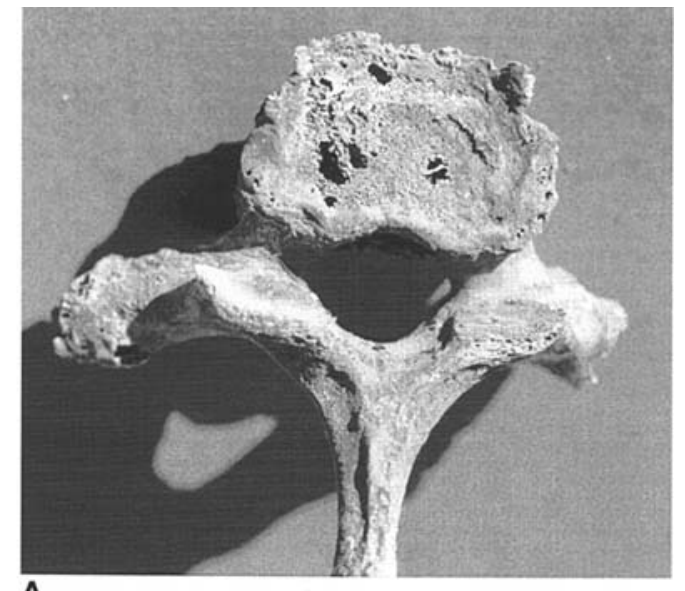

A

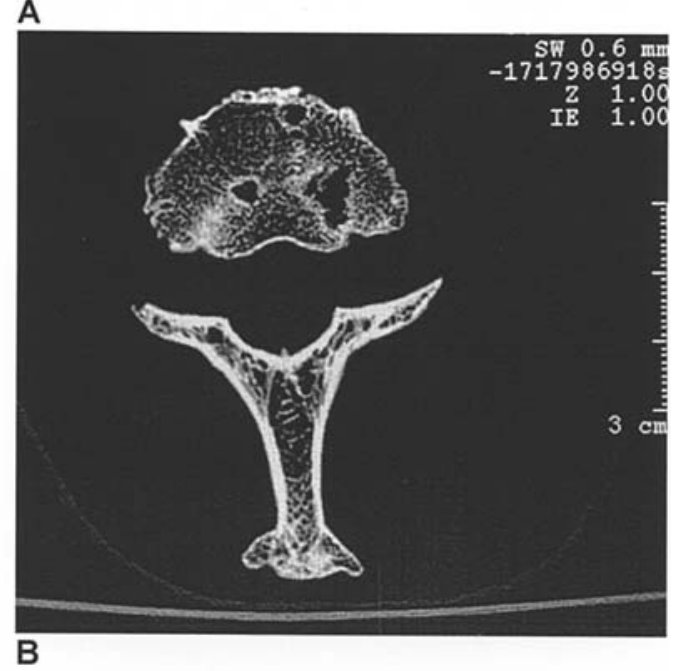

Figure 2. Macroscopic aspects of malignant tumors in ancient Egyptian skeletons. (A) Case 5 showing multiple vertebral osteolyses strongly suggestive for bone metastases of a soft tissue carcinoma. (B) The CAT scan demonstrates the multiplicity of the lesions and the osseous reaction at the margins.

the skeletal remains are present. However, these are of excellent preservation, including the biomatrix as evidenced from our recent molecular studies on tuberculosis in that population (9).

The second population comes from a Middle Kingdom tomb (c. 2100-1600 BC) from the necropolis of Thebes-West (TT-196) that has exclusively been used in that period (10). These individuals were moderately well artificially embalmed. Due to excellent climatic conditions this material, though mostly skeletonized, provides also excellent preservation status. The study population covers 211 individuals of intermediate social status.

The third group of ancient Egyptians under examination comes also from the necropolis of Thebes-West and covers the time between the New Kingdom until Late Period (c. 1500-500 BC). While the New Kingdom material comes from one of the most prosperous periods in ancient Egyptian history, the material from later periods also covers individuals living under significantly poorer living conditions. Due to the archaeological findings, most material belonged to individuals of advanced social status (11). In this group, a total of 505 individuals were investigated. 


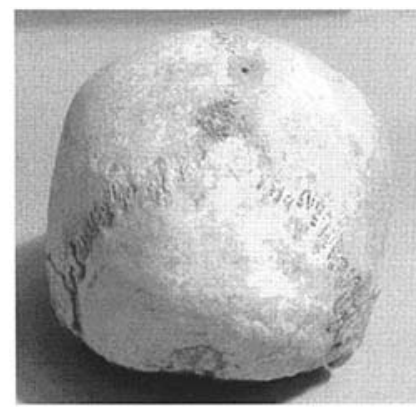

A

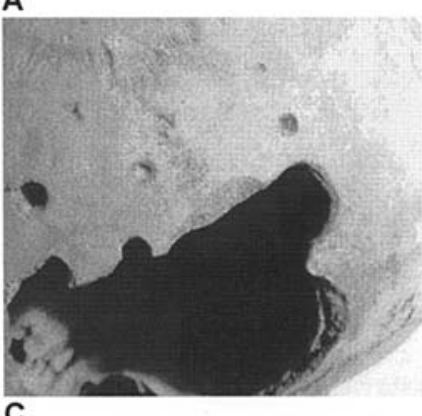

C

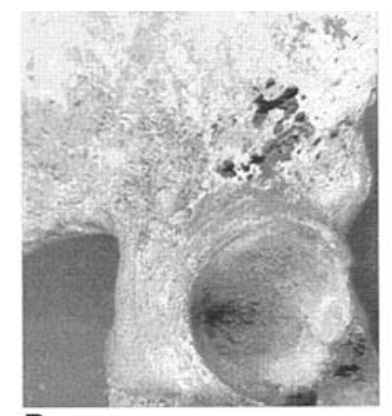

B

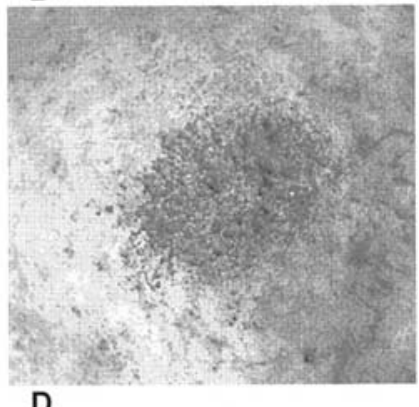

D

Figure 3. Macroscopic aspects of malignant tumors in the Southern German skeletons. (A) Multiple osteolyses (case 1) in an adult female skull. The lesions show a mixed osteolytic-osteoblastic reaction and are suggestive for metastatic carcinoma. (B) The same case (1) also reveals multiple other osteolytic lesions, such as shown here for the pelvis. (C) This case (case 2) of an adult male skull shows multiple osteolytic defects with only minimal bone reaction. This suggests a plasmacytoma (multiple myeloma). (D) The skull of an adolescent female individual (case 6) reveals tumor-associated new bone formation. This osteoblastic lesions is suggestive for an osteosarcoma of the skull.

Southern German material. The second study population comes from the small Southern German town of Rain/Lech, which was founded in $1250 \mathrm{AD}$ as a frontier fortress. Therefore, the city was surrounded by a wall allowing only restricted space for the cemetery that was located close to the church in the centre of the city. Due to these space restrictions, the human remains had to be removed after decomposition of soft tissues and the skeleton was transferred to an ossuary. Due to archaeological evidence, the ossuary in its present form was built in $1400 \mathrm{AD}$ so that the containing human remains date back to this time period. In $1803 \mathrm{AD}$, the in-town cemetery was eliminated and all further individuals were buried in an external cemetery. The skeletal remains from the ossuary therefore cover the time period of c. 1400-1800 AD.

Additionally, we have numerous data on the general town population of Rain/Lech in that time period and can estimate therefore the relative proportion of our observations on a general population basis.

The complete and careful examination of the human remains provided at least 2547 individuals buried in the ossuary as evidenced by the number of skulls that we could identify. The number of long bones (femora, tibiae etc.) was little lower indicating that the number of individuals obviously was not higher than estimated from the skull count (12).

Analytical procedure. In order to perform a study of tumor prevalence in the two aforementioned study populations, we performed a careful and extensive anthropological and paleopathological study of that material. This was enabled by the use of a special data system called 'mummy analysis data system' (MADS; 13), which administered all objects and their relevant data.

Thereby, the individuals were anthropologically classified as male or female adults and age at death was determined on the basis of established protocols (14). Thereby, a virtual reconstruction of the study populations was possible in the Egyptian material by $>65 \%$ individuals typed for age and gender and $58 \%$ individuals similarly typed in the Southern German material.

All human remains were furthermore extensively and carefully investigated with respect to absence or presence of traces of malignant tumors, which was part of a general paleopathological analysis of all material. Samples with clear evidence for malignant growth as well as those with potential diagnosis of a malignant tumor were subsequently analyzed by radiographs or CT scan in order to determine a differential diagnosis and to further elucidate the correct diagnosis. A subtyping of tumors was performed on the basis of criteria as previously established (15).

In an attempt to determine the relative tumor frequency on a population basis we used the anthropological data of individual age and sex distribution and applied these data and the observed tumors on the model population as determined by Waldron (7). In that study, the frequency of malignant tumors with osseous involvement of two distinct English populations dating either from 1901 to 1905 or from 1992 was used. The database allows an estimation of the boneassociated tumor frequency in the respective population taking age- and sex-dependent differences of the tumor frequency into consideration. Thereby, an upper and lower limit of expected tumor frequency can be calculated.

\section{Results}

Ancient Egyptian populations. In the material from ancient Egypt a total of 5 cases with clear macroscopic and radiological evidence of malignant tumor infiltration were identified (Figs. 1 and 2). They were diagnosed as malignant tumors due to their destructive growth pattern, which was mainly osteolytic. In all cases, additionally, a minor osteoblastic reaction was evident at the lytic lesion margins and which was even better seen in the X-rays and/or CT-scans. All cases presented as multiple lesions. In 3 cases, there were mixed osteolytic and -blastic lesions which are highly suspected for metastatic carcinoma (Figs. 1A-C , 2). In 2 further cases, the lesions were mostly lytic with only minimal osteoblastic reaction so that they were most likely classified as plasmacytoma (Fig. 1D). Details on affected localizations and individual data are given in Table I.

All cases were observed in the material dating back to the New Kingdom until Late Period, but none was seen in the older material (pre-/early dynastic and Middle Kingdom). Thereby, in our series the earliest tumor case dates back to max. $1500 \mathrm{BC}$.

The affected cases covered an age range between 20 and 60 years on the basis of the anthropological examination. Despite this wide age range, however, 4 cases ranged between 
Table I. Summary of ancient Egyptian malignant tumor cases.

\begin{tabular}{lllll}
\hline Age & Gender & \multicolumn{1}{c}{ Localization } & Osteoblastic/lytic & Presumed diagnosis \\
\hline $40-50$ & Female & Skull, vertebrae. humerus & Mixed & Metastases (carcinoma) \\
$20-25$ & Male & All skeletal regions & Mixed & Metastases (carcinoma) \\
$40-50$ & Male & Pelvis, vertebrae & Purely lytic & Plasmacytoma \\
$50-60$ & Male & Skull, vertebrae & Purely lytic & Plasmacytoma \\
$30-50$ & Female & Skull, vertebrae & Mixed & Metastases (carcinoma) \\
\hline
\end{tabular}

Table II. Description of Southern German bone tumor cases.

\begin{tabular}{lllll}
\hline Age & Gender & Localization & Osteoblastic/lytic & Presumed diagnosis \\
\hline $30-40$ & Female & Skull, pelvis & Mixed & Metastases (carcinoma) \\
$40-50$ & Male & Skull & Purely lytic & Plasmacytoma \\
$40-50$ & Male & Skull & Mixed & Metastases (carcinoma) \\
$>60$ & Male & Skull, long b. & Mixed & Metastases (carcinoma) \\
$20-30$ & Female & Skull & Mixed & Metastases (carcinoma) \\
$18-20$ & Female & Skull & Osteoblastic & Osteosarcoma? \\
$30-40$ & Male & Skull & Mixed & Metastases (carcinoma). \\
$30-40$ & Female & Skull, verteb. & Purely lytic & Plasmacytoma \\
$50-60$ & Male & Skull & Mixed & Metastases (carcinoma) \\
$50-60$ & Female & Skull & Mixed & Metastases (carcinoma) \\
$30-40$ & Male & Skull & Mixed & Metastases (carcinoma) \\
$50-60$ & Male & Skull & Mixed & Metastases (carcinoma) \\
$30-40$ & Male & Skull & mixed & Metastases (carcinoma) \\
\hline
\end{tabular}

40 and 60 years and only one case was in a younger age group. Two cases affected females and three were seen in males thereby showing a fairly balanced gender ratio.

The final diagnosis is uncertain in all cases. However, there are some favourite differential diagnoses that might be taken into consideration. Likewise, those cases with mixed lytic and blastic osseous reaction can most likely be attributed to metastatic carcinomas. The case in the younger individual is noteworthy, since the early age is most likely indicative for an embryonic carcinoma, such as seen in testicle cancer. The 2 cases with predominant osteolytic reaction (and the multiplicity of lesions) are more suggestive for plasmacytoma. None of our cases was indicative of primary or metastatic sarcoma affecting bone.

Ancient Southern German material. In the Southern German material of at least 2547 individuals, we identified 13 cases of malignant tumor growth manifesting in the skeleton. The details of these cases are presented in Table II. On the morphological/radiological basis again most presented as mixed osteolytic and osteoblastic lesions and several cases showed multiple lesions. Thereby, the morphology of most cases was very similar to that seen in the ancient Egyptian cases. In detail, 10 cases were mixed osteolytic and osteoblastic (Fig. 3A,B), 2 cases showed almost purely osteolytic lesions (Fig. 3C) and 1 case presented with significant bone reaction indicating tumor-associated new bone formation (Fig. 3D).
Again the affected individuals covered an age range between late juvenile (i.e. c. 18 years) to senile age ( $>60$ years) with most cases seen in the advanced age group. Accordingly, 5 cases were seen in an age range of $>50$ years, further 6 cases were between 30 and 50 years, 1 case was that of a younger woman between 20 and 30 and one that of a late adolescent female individual. Eight males opposed 5 females indicating a male dominance and an unbalanced gender ratio, in contrast to the Egyptian population.

The final diagnoses remain uncertain also in this study group. However, the morphological pattern and the age distribution were very suggestive in 10 cases for metastatic carcinomas, while 2 purely lytic growth patterns more favour the diagnosis of plasmacytoma. In the late adolescent female individual showing a strong osteoblastic reaction, we suggest the differential diagnosis of either (osteoblastic) osteosarcoma or (osteo-inductive) meningioma. However, since the main tumor mass extended to the external surface of the skull, the meningioma diagnosis is less likely, so that we favour, despite the young age for skull osteosarcoma, this latter diagnosis in this case.

Estimation of relative tumor frequencies on an epidemiologic basis. In a further attempt to estimate the frequency of malignant tumors on a population basis, we used for both populations the calculation model established by Waldron (7). This has been estimated on the basis of the frequency of 
osseous tumors in a well-defined population from England dating from between AD 1900 and 1905. Accordingly, we calculated in our two series the estimated frequencies of malignant tumors on a population basis. These data are determined in four different age groups (children to 18 years; 19-45 years; 46-60 years; and >60 years) and within the two gender groups (male/female).

The Egyptian material comprised a total of 905 individuals. A subdivision into the three time and space delineated populations was abandoned since the resulting populations were too small for further statistical analysis. The Southern German material was calculated on the basis of 2547 individuals as determined by a skull/skull fragment count.

The calculation of the estimated tumor frequency in the ancient Egyptian population yielded a theoretical number of between 8.45 (upper limits) and 4.13 (lower limits) tumor cases when the age- and gender-adjusted numbers were used. Rounded up or down to full numbers, this means that between 4 and 9 malignant tumors could have been expected in that material.

In the Southern German population between 19.69 (upper limits) and 10.56 (lower limits) cases of malignant tumors have been expected. In full numbers we might have seen between 11 and 20 tumor cases in this study population when we would have used the reference population from England from 1900 to $1905 \mathrm{AD}$.

\section{Discussion}

Despite the previously reported rarity of the traces of malignant tumors in the human remains of ancient populations (1-3) we describe in both our populations a considerable number of malignant tumors that had been engraved in osseous remains. This may be due to the excellent preservation status of our study material which has particularly been described for the ancient Egyptian mummies and skeletons (11) and which holds also true for the German material which has been stored in an ossuary. Likewise, our previous studies have shown in both populations the very good conservation of ancient bacterial DNA $(9,12)$. Furthermore, a further contributing factor to the obviously frequent tumor diagnosis might have been our very careful interdisciplinary paleopathological study including radiological/CT-analysis in selected cases.

The respective diagnoses were based on the presence of mostly multiple osteolytic defects in various bones with frequently typical osseous reaction. This strongly suggests multifocal tumor growth. All alternatively considered diagnoses, such as multifocal osteomyelitis, hyperparathyreoidism and others, are very unlikely due to the morphology and the distribution pattern of the lesions. Furthermore, with few exceptions the age and gender spectrum is well in agreement with the tumor diagnoses that we have established. The two exceptional cases of multiple mixed osteolyticosteoblastic lesions in younger individuals may represent metastatic tumors of the embryonic carcinoma type, although a definite tumor type diagnosis cannot be provided.

Similarly, we can only speculate on the underlying primary tumors in all other cases, the predominant multiplicity of defects with osteolyses mostly suggests carcinoma metastasis. This is well in line with the distribution of malignant tumors in bone in present day populations where carcinoma metastases represent $\sim 95 \%$ of all cases, followed by plasmacytoma which account for only $<5 \%$ and malignant primary bone tumors (osteosarcoma, chondrosarcoma, malignant soft tissue sarcomas) representing $<1 \%$ (15). Although the absolute proportions in our two populations are somehow divergent to these numbers the general proportions seem to be preserved.

Very few previous studies exist reporting tumor frequencies in paleopathological material. The data for ancient Egypt indicate tumor frequencies of between $0.24 \%$ ( 1 malignant tumor out of 403 cases; 16), $0.33 \%$ (4 out of 1180 individuals; 17 ), $0.45 \%$ ( 1 out of 222 cases; 18$), 0.62 \%$ ( 1 out of 160 cases; 19 ) and $2.85 \%$ (2 out of 70 cases; 20 ). In European populations of various time periods very similar frequencies have been reported: Wiltschke-Schrotta et al (21) described $2.5 \%$ malignant tumors (1 out of 39 cases), Pálfy (22) reports about $0.57 \%$ malignant tumors (3 out of 518 individuals) and Strouhal et al (23) about $0.5 \%$ (3 out of 554 individuals). However, these data are of only little value for comparison, since they did not take into account the population structure with respect to age and gender. The latter, however, is of major significance since malignant tumors usually occur much more frequent in older age.

In order to overcome these previous shortcomings, we calculated the frequency of malignant tumors in the overall population of mummified residues of several tombs that have as yet been carefully investigated in the necropolis of ThebesWest and the skeletons of the Southern German population. Thereby, we have investigated two populations of considerable size of at least 905 and 2457 individuals providing an adequate basis that starts to allow more precise statistical data than in our previous study on several of our Egyptian cases (5). All Egyptian tumor cases were seen only in the New Kingdom until Late Period (i.e. between c. 1500 and $500 \mathrm{BC}$ ), but not in earlier time periods. Although we have still too few individuals analyzed in the early until predynastic and the Middle Kingdom periods, this may suggest lower tumor frequencies in the early Egyptian time periods. However, this assumption may be revised after the study of further cases and larger populations. Accordingly, we did not calculate relative tumor frequencies for the three ancient Egyptian time periods.

In order to provide comparable data between historic and 'modern' times and between various historic study populations, as in this study, we used an estimation model that has previously proved to be very helpful. Several years ago, Waldron (7) provided a model for the estimation of the tumor frequency on a population basis. By comparison with a defined 'control' population from England at the beginning of the 20th century and referring to the age- and sex-structure of the population under investigation, one can calculate the tumor frequency and compare it to the expected value on the basis of the English control population. The only previous study using this calculation model is ours by Zink et al (5) which showed that the expected tumor frequency was within that of the modern English one. Herein, we can clearly confirm this notion and can add further data: The extension of our study population in the Egyptian material shows again a tumor frequency within the Waldron reference group of modern England. Furthermore, the additional study 
population from Southern Germany showed also a tumor frequency that was within the expected range.

In our study, we provide one of the first studies on the paleoepidemiology of malignant tumors on the basis of comparative and age-/gender-adjusted values. Thereby, we can show that malignant tumors were not significantly fewer than expected when compared to a 'modern' early 20th century English population. The most important issue to this respect is to take the significantly shorter life expectancy of historic and early modern populations into account. Thereby, the obviously low number of malignant tumors is due to the short life expectancy in historic populations. In turn, this clearly outlines that genetic and initial environmental factors may not be so relevant for the tumorigenesis, as the influence of nutrition, infections and other factors may be with lasting life. To this respect, the duration of an external influence seems to be a much more significant parameter.

Having started with this kind of tumor paleoepidemiology, we will now proceed into two directions: i) we will try to extend our paleopathological analysis to other populations from different locations and time periods, and 2), we will try to compile as much information as possible on general living conditions, including nutrition, infectious diseases, and environmental stress in order to evaluate the potential risk factors for cancer induction in the history of mankind.

\section{References}

1. Pahl WM: Tumors of bone and soft tissue in ancient Egypt and Nubia: a synopsis of the detected cases. Int $\mathbf{J}$ Anthropol 1: 267-276, 1986.

2. Strouhal E: Malignant tumors of the old world. Palaeopathol Newslett 85: 1-6, 1994.

3. Ricci R, Lama R, Di Tota G, Capelli A and Capasso L: Some considerations about the incidence of neoplasms in the human history. J Paleopathol 7: 5-11, 1995.

4. Micozzi MS: Disease in antiquity. The case of cancer. Arch Pathol Lab Med 115: 838-844, 1991.

5. Zink A, Rohrbach H, Szeimies U, Hagedorn H, Haas C and Nerlich AG: Malignant tumors in an ancient Egyptian population. Anticancer Res 19: 4273-4278, 1999.

6. Bachmeier B, Zink A, Rohrbach H, Szeimies U and Nerlich AG: A metastatic malignant tumor in an ancient Egyptian vertebra. In: Proceedings XIIIth European Meeting of the Paleopathology Association. La Verghetta M and Capasso L (eds). Edigrafital, Teramo, Italy, pp17-22, 2001.

7. Waldron T: What was the prevalence of malignant disease in the past? Int J Osteoarcheol 6: 463-470, 1996.
8. Dreyer G, Hartmann R, Hartung U, Köpp H, Lacher C, Müller A, Nerlich A and Zink A: Umm el-Qaab - Nachuntersuchungen im frühzeitlichen Königsfriedhof 13./14./15. Vorbericht. Mitteilungen des Deutschen Archäologischen Institutes in Kairo (MDAIK) 59: 49-64, 2003.

9. Zink AR, Grabner W, Reischl U, Wolf H and Nerlich AG: Molecular study on human tuberculosis in three geographically distinct and time delineated populations from ancient Egypt. Epidemiol Infect 130: 239-249, 2003.

10. Das Grab des Padihorresnet, Obervermögensverwalter der Gottesgemahlin des Amun (Thebanisches Grab Nr. 196). Graefe E (ed). Monumenta Aegyptiaca IX, Turnhout, 2003.

11. Nerlich A, Rohrbach $\mathrm{H}$ and Zink A: Paläopathologie altägyptischer Mumien und Skelette. Untersuchungen zu Auftreten und Häufigkeit spezifischer Krankheiten in verschiedenen Zeitperioden der altägyptischen Nekropole von Theben-West. Pathology 23: 379-385, 2002.

12. Haas CJ, Zink A, Szeimies U, Palfi G and Nerlich AG: Detection of leprosy in ancient human skeletal remains by molecular identification of Mycobacterium leprae. Am J Clin Pathol 114: 428-436, 2000.

13. Rohrbach H, Betz A, Nerlich AG and Zink A: Computer-based analysis of the paleopathological findings in the human remains of the necropolis in Thebes-West. In: Proceedings XIIIth European Meeting of the Paleopathology Association. La Verghetta M and Capasso L (eds). Edigrafital, Teramo, Italy, pp261-264, 2001.

14. Ferembach D, Schwidetzky I and Stloukal M: Empfehlungen für die Alters- und Geschlechtsdiagnose am Skelett. Homo 30: $1-32,1979$.

15. Nerlich A, Zink A and Löhrs U: Differential diagnosis of tumorous skeletal lesions in historic tissues. ERES (Arqueologia) 7: 87-103, 1997.

16. Armelagos GJ: Disease in ancient Nubia. Science 163: 255-259, 1969.

17. Rösing FW: Qubbet el Hawa und Elephantine. Zur Bevölkerungsgeschichte von Ägypten. Gustav Fischer, Stuttgart, Germany, pp46-95, 1990.

18. El-Rakhawy MT, El-Eishi HI, El-Nofely A and Gaballah MF: A contribution to the pathology of ancient Egyptian skulls. Anthropology 9: 71-78, 1971.

19. Strouhal E: Tumors in the remains of ancient Egyptians. Am J Phys Anthropol 45: 613-620, 1976.

20. Strouhal E and Vyhnanek L: New cases of malign tumours from Late Period cemeteries at Abusir and Saqqara (Egypt). Ossa 8: 165-189, 1982.

21. Wiltschke-Schrotta K, Teschler-Nicola M, Lyle A and Schultz M: Occurence of tumors within skeletal remains from a late antique burial site in Linz, Austria. Palaeopathol Newslett 86 (Suppl): 15,1995

22. Pálfy GY: The occurrence of bone tumors in the anthropological remains belonging to the Szekkutas-Kapolnadülö cemetery (Hungary) of the late Avar period. Acta Biol Szeg 35: 207-220, 1989.

23. Strouhal E, Vyhnanek L, Horackova L, Benesova L and Nemeckova A: Five newly detected Medieval and early modern cases of cancer from Moravia (Czech Republic). Palaeopathol Newslett 86 (Suppl): 16, 1995. 